\title{
Nova metodologia para análise comparativa da liberação de flúor de cimentos de ionômero de vidro restauradores e compômeros*
}

\author{
New methodology for comparative analysis of the fluoride release of glass-ionomer \\ cement and compomers
}

Fernanda de Carvalho Panzeri PIRES-DE-SOUZA

Professora Associada do Departamento de Materiais Dentários e Prótese - Faculdade de Odontologia de Ribeirão Preto Universidade de São Paulo - USP - Ribeirão Preto - SP - Brasil

Allyson Wesley de Almeida ZARONI

Cirugião-dentista - Universidade de Franca - UNIFRAN - Franca - SP - Brasil

\section{Lucas da Fonseca Roberti GARCIA}

Doutorando em Materiais Dentários - Faculdade de Odontologia de Piracicaba - Universidade Estadual de Campinas UNICAMP - Piracicaba - SP - Brasil

\section{Diogo Rodrigues CRUVINEL}

Mestrando em Reabilitação Oral - Faculdade de Odontologia de Ribeirão Preto - Universidade de São Paulo - USP Ribeirão Preto - SP - Brasil

\section{Luciana Assirati CASEMIRO}

Professora Doutora do Curso de Odontologia - Universidade de Franca - UNIFRAN - Franca - SP - Brasil

\begin{abstract}
Resumo
Esse trabalho apresentou nova metodologia para avaliar a liberação dinâmica de flúor de três materiais, um cimento de ionômero de vidro restaurador (Vidrion R), um ionômero de vidro modificado por resina (Vitremer) e um compômero (Dyract AP). Após manipulação dos materiais segundo recomendações dos fabricantes e da obtenção dos corpos-deprova, os mesmos foram armazenados em saliva artificial sem flúor por 30 dias. A concentração de fluoreto nas soluções estoque foram determinadas com um potenciômetro, utilizando um eletrodo íon seletivo para fluoreto (Orion $\mathrm{n}^{\circ} 9609$ BN) conectado a um registrador (HANNA Instruments HI n ${ }^{\circ}$ 9321). Os resultados indicaram um melhor comportamento do ionômero de vidro convencional, seguido do ionômero modificado e posteriormente do compômero.
\end{abstract}

\section{UNITERMOS}

Flúor; cimento de ionômero de vidro; compômero.

\section{INTRODUÇÃo}

Os fabricantes e pesquisadores de materiais dentários procuram desenvolver produtos que reúnam, ao máximo, as características de biocompatibilidade, resistência, estética, facilidade de manipulação e ação anticariogênica. A obtenção dessa última característica se dá pela liberação de fluoreto, incorporado num número cada vez maior de materiais restauradores como amálgama (Jerman $\left.{ }^{16}, 1970\right)$, resinas compos- tas (Arends et al. $\left.{ }^{1}, 1990\right)$, ionômeros e compômeros (Ciccone et al. $\left.{ }^{6}, 2004\right)$.

O flúor tem sido utilizado há muito tempo como auxiliar na prevenção da cárie, uma vez que proporciona a estabilização das estruturas cristalinas do esmalte e melhora sua resistência ao ataque ácido promovido pelas bactérias. Age ainda inibindo a enolase, uma enzima da via glicolítica bacteriana que converte 2-fosfoglicerato a fosfoenolpiruvato (Larsen e Brun ${ }^{19}$, 1986; Newbrun ${ }^{23}$, 1986).

* Trabalho de conclusão do curso de odontologia da UNIFRAN. 
A liberação de flúor de um material depende de vários fatores, como sua composição (Forsten ${ }^{12}$ 1990; Takahashi et al. ${ }^{29}, 1993$ ), solubilidade (Tveit e Gjerdet $^{30}$, 1981; DeSchepper et al. ${ }^{8}, 1991$; Takahashi et al. ${ }^{29}, 1993$ ), porosidade (DeSchepper et al. ${ }^{8}, 1991$ ) e características de presa. Enquanto os cimentos de ionômero de vidro convencionais apresentam reação do tipo ácido/base, capaz de formar um sal de hidrogel que atua como matriz de ligação, a reação de presa do compômero é caracterizada pela polimerização dos grupamentos metacrilatos dos monômeros resinosos convencionais (UDMA e Bis-GMA) e de monômeros modificados com caráter bifuncional, com grupamentos carboxílicos em uma das extremidades e grupamentos metacrilatos na outra; isso permite a polimerização através dos grupamentos metacrilatos e sua posterior ionização na extremidade carboxílica para atacar as partículas parcialmente silanizadas e proporcionar reação ácido/base. A fotopolimerização aparentemente reduz os níveis de reação ácido/base prejudicando a maturação da fase vítrea na camada superficial externa (Kakaboura et al. $\left.{ }^{17}, 1996\right)$. Isso pode levar à diminuição da liberação de fluoreto (Geurtsen et al. ${ }^{14}$, 1999) e, consequientemente, a menor ação anticariogênica do material. Swartz et al. ${ }^{28}$ (1984) observaram que os padrões e a quantidade de fluoreto liberado por cimentos de ionômeros de vidro convencionais são similares aos dos cimentos de silicato.

O meio em que esses materiais são mantidos, nos estudos in vitro, interfere na liberação de fluoreto (Geurtsen et al. ${ }^{14}$, 1999). Para Friedl et al. ${ }^{13}$ (1997), o compômero libera significantemente menos fluoreto que os ionômeros convencionais ou modificados por resina em meio aquoso.

Este trabalho verificou a liberação dinâmica de flúor de dois cimentos de ionômero de vidro restauradores e de um compômero quando armazenados em saliva artificial sem flúor por um período de 30 dias.

\section{Material e métodos}

Os materiais avaliados quanto à liberação de flúor foram o compômero Dyract AP (Dentsply Indústria e Comércio Ltda, Petrópolis, RJ, Brasil, lote 9803001441) e os cimentos de ionômero de vidro restauradores Vitremer (3M, Sumaré, SP, Brasil, lote 20010327) e Vidrion R (SSWhite, Rio de Janeiro, RJ, Brasil, lote 00E).

Os materiais foram manipulados segundo recomendações dos fabricantes e inseridos numa matriz circular $(10,0 \times 1,5 \mathrm{~mm})$, sobre a qual foi colocada uma placa de vidro para regularização da superfície. Quando indicado, foi realizada a fotopolimerização (XL 3000, 3M Espe, Sumaré, SP, Brasil; 450/500mW/ $\mathrm{cm}^{2}$ ) por 60s. em cada lado do corpo-de-prova. Foram obtidos seis corpos-de-prova para cada material.

Foi desenvolvido um equipamento (Figura 1) para a realização do experimento, composto por uma mangueira plástica transparente $(2,5 \mathrm{~cm}$ de diâmetro interno) cortada em 18 pedaços de $8,0 \mathrm{~cm}$, nos quais foram colocados os corpos-de-prova. Suas extremidades foram vedadas com dois tampões de tubo de pvc (Tigre, Joinvile, $\mathrm{SC}$, Brasil), que se encaixavam perfeitamente. O distribuidor (Figura 2) de saliva artificial (Farmácia-Ensino da Faculdade de Ciências Farmacêuticas de Ribeirão Preto, USP, Ribeirão Preto, SP, Brasil, pH7,0) consistiu em um tubo de pvc de $1 / 2$ polegada (Tigre, Joinvile, $\mathrm{SC}$, Brasil), no qual foram feitos furos seqüenciais para encaixe das cânulas que conectavam o distribuidor e os recipientes com os corpos-de-prova. Entre esses componentes, havia um regulador de fluxo que proporcionava a passagem de $5,0 \mathrm{~mL}$ ao final de $24 \mathrm{~h}$, período no qual a solução foi substituída. O controle térmico das amostras foi realizado por 9 lâmpadas de 12 volts em série, de forma que, para cada lâmpada, havia dois recipientes de corpos-de-prova, resultando numa temperatura de $37^{\circ} \mathrm{C}$. Nos recipientes dos corpos-de-prova havia uma cânula de saída correspondente à ligação entre eles e os recipientes de coleta, que consistiu numa embalagem de filme radiográfico. Para cada recipiente de corposde-prova havia um recipiente de coleta.

A dinâmica do equipamento está descrita a seguir. A saliva saiu de um reservatório localizado 2,0m acima do equipamento, percorrendo uma cânula e chegando ao distribuidor. Nesse local, ela foi dividida para cada uma das cânulas que passava pelo regulador e seguiu para os recipientes de corpos-de-prova, passando pelos mesmos e sendo posteriormente depositada nos recipientes de coleta. Até a obtenção de todas as amostras de solução, as mesmas foram armazenadas em geladeira $\left(8^{\circ} \mathrm{C}\right)$. Antes da análise da concentração de fluoreto, foi medido o volume final de cada amostra diária.

A concentração do íon fluoreto foi determinada pelo método potenciométrico usando um eletrodo íon seletivo para fluoreto (Orion $n^{\circ} 9609 \mathrm{BN}$, Orion Research Inc., Boston, MA) conectado a um potenciometro (HANNA Instruments $\mathrm{HI}^{\circ}$ 9321, Woonsocket, RI, USA) e calibrado com soluções aquosas padrão contendo 0,$1 ; 0,2 ; 0,4 ; 1,0 ; 2,0 ; 4,0 ; 10,0$ e $20,0 \mathrm{ppm}$ de fluoreto, antes e após a leitura das amostras, para compensar qualquer alteração causada por variações de temperatura umidade. 
NOVA METODOLOGIA PARA ANÁLISE COMPARATIVA DA LIBERAÇÃO DE FLÚOR DE CIMENTOS DE IONÔMERO DE VIDRO RESTAURADORES E COMPÔMEROS

\section{Resultados e discussão}

O compômero Dyract apresentou o seguinte perfil de liberação de fluoreto: no primeiro dia, houve liberação média de $0,3 \mathrm{ppm}$, a qual foi crescente até o quinto dia, quando se observou o ponto máximo de liberação $(1,8 \mathrm{ppm})$, porém sem a ocorrência de um pico elevado. A partir do quinto dia a liberação foi decrescente, atingindo o valor inicial $(0,3 \mathrm{ppm})$ no vigésimo primeiro dia de experimento e mantendo-se aproximadamente constante até o final do tempo prédefinido para a conclusão do experimento.

O ionômero modificado Vitremer apresentou, já no primeiro dia de experimento, liberação média de fluoreto de $1,7 \mathrm{ppm}$, que aumentou até o quarto dia, quando se observou um pico correspondente a 3,6ppm. Em seguida, observou-se liberação decrescente, atingindo estabilidade no vigésimo segundo dia, correspondente a $0,3 \mathrm{ppm}$. A partir desse dia, a liberação permaneceu constante até o final do experimento.

Observou-se para o Vidrion R liberação média inicial (primeiro dia) de $4,1 \mathrm{ppm}$, a qual se apresentou crescente, atingindo seu pico no terceiro dia de experimento $(8,1 \mathrm{ppm})$. A estabilidade na liberação foi atingida no vigésimo sexto dia do experimento, com valores médios de $0,5 \mathrm{ppm}$. A comparação dos resultados obtidos para todos os materiais pode ser visualizada no Gráfico 1.

O uso do flúor está consagrado na Odontologia (Newbrun ${ }^{26}$ 1986), sendo uma tendência sua incorporação também nos materiais dentários (Jerman ${ }^{16} 1970$, Arends et al. ${ }^{1}$ 1990, Ciccone et al. $\left.{ }^{6}, 2004\right)$. Idealmente, a liberação de flúor pelos materiais deveria se dar em baixa intensidade, com velocidade constante e por um longo tempo (Larsen e Brun ${ }^{19}$, 1986).

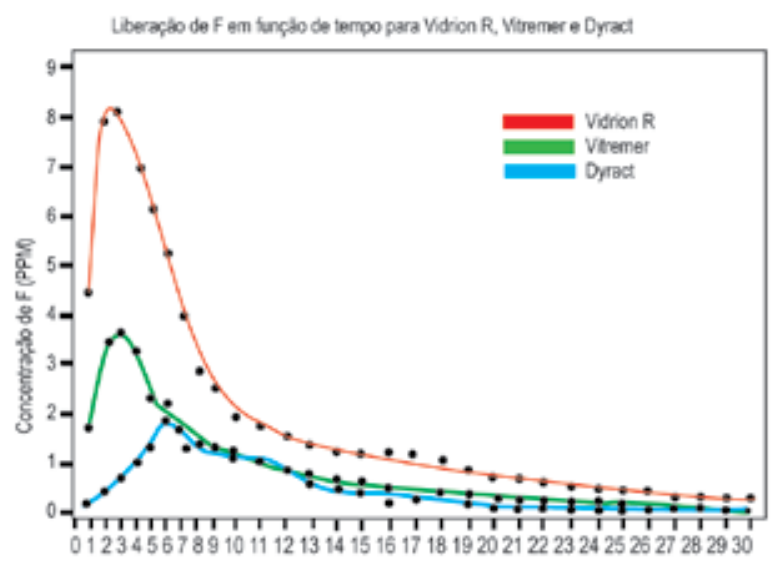

GRÁFICO 1 - Comparação dos comportamentos dos materiais estudados.
A manutenção constante de flúor no meio bucal é uma condição ideal, uma vez que possibilita a formação contínua da apatita fluoretada. Isso pode ser explicado pelo fato de que pessoas que ingeriram flúor por toda a vida e por algum motivo suspenderam seu uso apresentam o mesmo perfil de cárie que aqueles que nunca fizeram uso desse íon (Russel ${ }^{26}, 1949$ ). O flúor incorporado ao dente, portanto, não é o único responsável por evitar a instalação e o desenvolvimento da doença cárie, sendo fundamental sua presença contínua no meio para a manutenção da integridade do esmalte. Segundo Mount ${ }^{22}$ (1998), o nível de íons fluoreto na saliva, na média dos pacientes, é em torno de $0,08 \mathrm{ppm}$ e só isso é suficiente para paralisar a doença cárie onde não há cargas exageradas. Esse nível pode ser aumentado de várias maneiras, o que é importante na remineralização (Exterkate et al. ${ }^{10}, 2005$ ).

Analisando os resultados apresentados, pode-se observar que os três materiais estudados tiveram perfis de liberação de fluoreto diferentes, com variação de seus picos em tempo e magnitude. Entretanto, todos eles estabilizaram suas liberações em torno do vigésimo sexto dia, apresentando semelhança quantitativa a partir desse momento. Em relação aos compômeros, esses resultados apresentam semelhança com os obtidos por Shaw et $\mathrm{al}^{27}$. (1998), que observaram liberação baixa e relativamente constante por todo o período de testes.

Alguns estudos indicam que os compômeros apresentam melhores propriedades físicas que os ionômeros de vidro, bem como menor abrasão, maior selamento marginal e liberação de flúor. Khouw-Liu et al. ${ }^{18}$ (1999) observaram liberação similar entre os dois materiais. Já Millar et al. ${ }^{21}$ (1998) e Bala et al. ${ }^{3}$ (1997) relataram que os compômeros apresentam menor capacidade inibitória que os cimentos de ionômero de vidro tradicionais. Neste trabalho, observou-se que o ionômero de vidro convencional liberou maior quantidade de flúor que o ionômero modificado, sendo a menor liberação proporcionada pelo compômero.

A análise dos resultados permite inferir que o fato do ionômero de vidro convencional (Vidrion R) liberar quantidade maior de fluoreto deve-se, provavelmente, ao fato que se trata de um material "puro", ou seja, sem adição de nenhum modificador, como acontece com a adição de resina para o ionômero de vidro modificado (Vitremer) e para o compômero, que nada mais é do que um resina modificada pela presença de polissais (Dyract). Dessa forma, a liberação de flúor pelos ionômeros convencionais se daria sem a interferência de outros componentes do material, que poderiam dificul- 
tar esse processo. Além disso, cimentos de ionômero de vidro convencionais apresentam, como a maioria dos cimentos odontológicos, alta desintegração nos meios bucais. E isso pode, de certa forma, aumentar a liberação de flúor, como relatado por Bertacchini et al. ${ }^{4}$ (1999).

A determinação da liberação de fluoreto de um material é dependente da metodologia utilizada, fato que, para $\mathrm{McCabe}^{20}$ (1998) deve ser considerado na discussão dos resultados. A freqüência de substituição da solução de armazenamento é um dos fatores mais críticos desses experimentos. Dunne et al. ${ }^{9}$ (1996) relataram que os níveis de flúor em soluções teste de compômeros podem equilibrar-se dentro de uma hora, enquanto que para ionômeros convencionais isso pode ocorrer dentro de 24 horas. Assim, optou-se pela substituição da solução a cada 24 horas, uma vez que isso poderia resultar numa menor interferência sobre os resultados, sendo verificada a liberação de flúor não cumulativa, como sugerido por Grobler et al. ${ }^{15}$ (1998).

Ainda em relação à metodologia utilizada, vários estudos relacionam a quantidade de liberação de flúor de um material à solução de armazenamento das amostras (Czarnecka et al. ${ }^{7}$ 2002, Nicholson e Czarnecka ${ }^{24}$ 2004). Os dados desse trabalho foram obtidos empregando-se saliva artificial com pH neutro. Entretanto, Carvalho e Cury ${ }^{5}$ (1999) e Attin et al. ${ }^{2}$ (1999) sugerem que sejam realizados testes também em $\mathrm{pH}$ ácido, para melhor simulação das condições encontradas na cavidade oral, que apresenta variações de composição

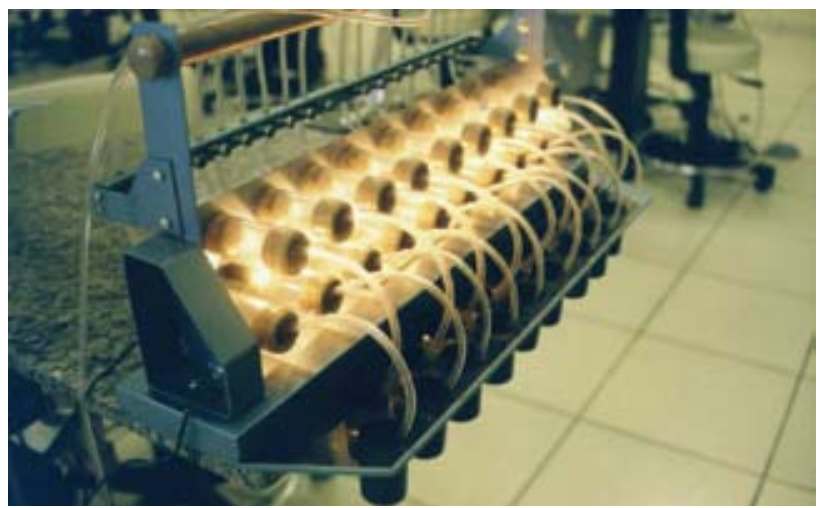

FIGURA 1 - Vista do equipamento. e fluxo salivar ao longo do dia (Rudney ${ }^{25}$, 1995, Flink et al. ${ }^{11}$ 2005), além de oscilação de $\mathrm{pH}$.

Um importante dado desse trabalho foi o desenvolvimento de uma metodologia para medir essa relevante propriedade de materiais restauradores com enfoque preventivo. Entretanto, outros estudos devem ser realizados, reproduzindo-se outras condições ambientais presentes no ambiente bucal e que poderiam interferir nos resultados, como a variação de $\mathrm{pH}$, para melhor compreensão desse processo de liberação de flúor pelos materiais restauradores.

\section{Conclusão}

De acordo com a metodologia empregada e com os resultados obtidos neste trabalho, pode-se concluir que:

1) $\mathrm{O}$ cimento de ionômero de vidro restaurador (Vidrion R) apresentou maior liberação de flúor, demonstrado pelo pico de liberação acentuado e níveis de estabilização superiores em relação aos demais materiais.

2) O cimento de ionômero modificado por resina ( $\mathrm{Vi}$ tremer) apresentou liberação de flúor intermediária aos outros dois materiais e níveis de estabilização semelhantes aos apresentados pelo compômero (Dyract).

3) O compômero (Dyract) não apresentou pico de liberação de flúor, mas manteve seus níveis de estabilização quase constantes.

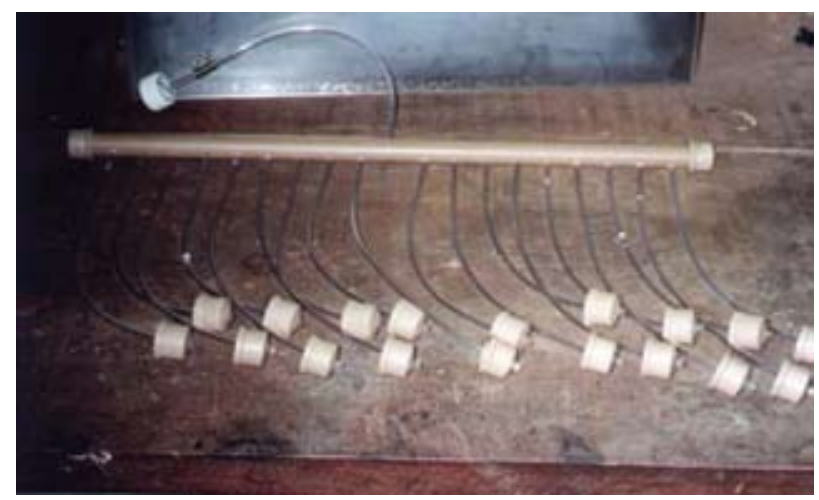

FIGURA 2 - Distribuidor de saliva. 


\section{Abstract}

This study developed a new methodology to evaluate the dynamic release of fluorine from three materials: one restorative glass-ionomer cement (Vidrion R), one resin-modified glass ionomer (Vitremer) and one compomer (Dyract AP). Specimens were obtained according to the manufacturer's recommendations and were stored in fluoride-free artificial saliva for 30 days. The fluoride concentration in the stored solutions were determined with a potentiometer, using a fluoride ion-selective electrode (Orion $n^{\circ} 9609 \mathrm{BN}$ ) connected to a meter (HANNA Instruments HI $\mathrm{n}^{\circ}$ 9321). The results revealed that the conventional glass ionomer showed the best behavior, followed by the resin-modified ionomer and, finally, the compomer.

\section{UNITERMS}

Fluor; glass ionomer; cement; compomer.

\section{REFERÊnCIAS}

1. Arends J, Ruben J, Dijkman AG. Effect of fluoride release from a fluoride-containing composite resin on secondary caries: an in vitro study. Quintessence Int. 1990; 21(8):671-4.

2. Attin T, Buchalla W, Siewert C, Hellwig E. Fluoride release/uptake of polyacid-modified resin composites (compomers) in neutral and acidic buffer solutions. J Oral Rehabil. 1999; 26(5):388-93.

3. Bala O, Üçtasli M, Can H, Túrkoz E, Can M. Fluoride release from various restorative materials. J Nihon Univ Sch Dent. 1997; 39(3):123-7.

4. Bertacchini SM, Abate PF, Blank A, Baglieto MF, Macchi RL. Solubility ad fluoride release in ionomers and compomers. Quintessence Int. 1999; 30(3):193-7.

5. Carvalho AS, Cury JA. Fluoride release from some dental materials in different solutions. Oper Dent. 1999; 24(1):214-9.

6. Ciccone JC, Verri MP, Navarro MFL, Salvador SL, Palma-Dibb RG. Avaliação in vitro do potencial antimicrobiano de diferentes materiais restauradores. Mat. Res. 2004; 7(2):231-4.

7. Czarnecka B, Limanowska-Shaw H, Nicholson JW. Buffering and ion-release by a glass-ionomer cement under near-neutral and acidic conditions. Biomaterials. 2002; 23(13):2783-8.

8. DeSchepper EJ, Berr EA, 3rd, Cailleteau JG, Tate WH. A comparative study of fluoride release from glass-ionomer cements. Quintessence Int. 1991; 22(3):215-9.

9. Dunne SM, Goolnik JS, Millar BJ, Seddont RP. Caries inhibition by a resin-modified and a conventional glass ionomer cement, in vitro. $\mathrm{J}$ Dent. 1996; 24(1-2):91-4.

10. Exterkate RA, Damen JJ, Ten Cate JM. Effect of fluoride-releasing filling materials on underlying dentinal lesions in vitro. Caries Res. 2005; 39(6):509-13.

11. Flink H, Tegelberg A, Lagerlof F. Influence of the time of measurement of unstimulated human whole saliva on the diagnosis of hyposalivation. Arch Oral Biol 2005; 50(6):553-9
12. Forsten L. Short- and long-term fluoride release from glass ionomers and other fluoride-containing filling materials in vitro. Scand J Dent Res. 1990; 98(2): 179-85.

13. Friedl KH, Schmalz G, Hiller KA, Shams M. Resin-modified glass ionomer cements: fluoride release and influence on Streptococcus mutans growth. Eur J Oral Sci. 1997; 105(1):81-5.

14. Geurtsen W, Leyhausen G, Garcia-Godoy F. Effect of storage media on the fluoride release and surface microhardness of four polyacidmodified composite resins ("compomers"). Dent Mater. 1999; 15(3): 196-201.

15. Grobler SR, Rossouw RJ, Van Wyk JK. A comparison of fluoride release from various dental materials. J Dent. 1998; 26(3):259-65.

16. Jerman AC. Silver amalgam restoration material with stannous fluoride. J Am Dent Assoc. 1970; 80(4):787-91.

17. Kakaboura A, Eliades G, Palaghias G. An FTIR study on the setting mechanism of resin-modified glass ionomer restoratives. Dent Mater. 1996; 12(3):173-8.

18. Khouw-Liu VHW, Anstice HM, Pearson GJ. An in vitro investigation of a poly (vinyl phosphonic acid) based cement with four convenional glass-ionomer cements. Part I: flexural strength and fluoride release. J Dent. 1999; 27:351-7.

19. Larsen MJ, Brun C. Enamel/saliva - inorganic chemical reaction. In: Thylstrup A, Fejerskov O. Textbook of Cariology. Copenhagem: Munksgaard: 1986; p.181-203.

20. McCabe JF. Resin-modified glass-ionomers. Biomaterials. 1998 19(6):521-7.

21. Millar BJ, Abiden F, Nicholson JW. In vitro caries inhibition by polyacid-modified composite resins ("compomers"). J Dent. 1998; 26(2):133-6.

22. Mount GJ. Clinical performance of glass-ionomers. Biomaterials 1998; 19(6):573-9. 
NOVA METODOLOGIA PARA ANÁLISE COMPARATIVA DA LIBERAÇÃO DE FLÚOR DE CIMENTOS DE IONÔMERO DE VIDRO RESTAURADORES E COMPÔMEROS

23. Newbrun E. Mechanism of fluoride action in caries prevention. In: Fluorides and dental caries. 3. ed. Springfield: Charles C. Thomas; 1986. p.55-173.

24. Nicholson JW, Czarnecka B. The release of ions by compomers under neutral and acidic conditions. J Oral Rehabil. 2004; 31(7):665-70.

25. Rudney JD. Does variability in salivary protein concentrations influence oral microbial ecology and oral health? Crit Rev Oral Biol Med 1995;6(4):343-67.

26. Russel AL. Dental effects of exposure to fluoride-bearing dakota sandstone waters at various ages and for various lengths of time: I. Status of the permanent teeth of 339 children aged 11 to 15 years who used such water for eighteen months prior to eruption of the first permanent molars. J. Dent. Res. 1949; 28:298-309.

27. Shaw AJ, Carrick T, Mccabe JF. Fluoride release from glass-ionomer and compomer restorative materials: a 6-month data. J. Dent. 1998; 26(4):355-9.

28. Swartz ML, Phillips RW, Clark HE. Long-term F release from glass ionomer cements. J Dent Res. 1984; 63(2):158-60.
29. Takahashi K, Emilson CG, Birkhed D. Fluoride release in vitro from various glass ionomer cements and resin composites after exposure to NaF solutions. Dent Mater 1993; 9(6):350-4.

30. Tveit AB, Gjerdet NR. Fluoride release from a fluoride-containing amalgam, a glass ionomer cement and a silicate cement in artificial saliva. J Oral Rehabil. 1981; 8(3):237-41.

Recebido em 11/06/07 Aprovado em 21/08/07

Correspondência Profa. Dra. Fernanda de Carvalho Panzeri Pires-de-Souza USP - FOPR Av do Café, s/n. - Monte Alegre 14040-904 - Ribeirão Preto - SP - Brasi e-mail: ferpanzeri@forp.usp.br 